\title{
O Modelo Político na Constituição do Império*.
}

\author{
Manoel Gonçalves Ferreira Filho \\ Professor Titular de Direito Constitucional na Fa- \\ culdade de Direito da Universidade de São Paulo.
}

\begin{abstract}
SUMÁRIo: IntrodUção. 1. A longa vida da Constituição do Império. II. A FoNTE do PODER POLÍtico. 2. O preambulo da Carta. 3. Principio autocrático e principio democrático na estruturação dos poderes. III. O PRINcípio AUTOCRÁtico. 4. Os quatro poderes de Constant. 5. A adoção do Poder Moderador. 6. O Poder Moderador na Carta. 7. Competência e significação do Poder Moderador. 8. O Poder Executivo. IV O PrINCípIo Democrático. 9. A representaçāo. 10. O sistema censitário na Carta. 11. As deficiências do sistema eleitoral. V. O Modelo PoLítico NA CoNSTITUIÇÃo Do IMPÉRIo. 12. A monarquia democratizante. 13. O Poder Moderador e o parlamentarismo no Império. 14. O mérito da Constituição.
\end{abstract}

\section{Introdução}

1 A Constituição do Império foi de todas as brasileiras a que por mais tempo vigorou. Promulgada a 25 de março de 1824, data em que Pedro I a outorgou e jurou, esteve em vigor até 15 de novembro de 1889 quando se proclamou a República. Assim, por cerca de sessenta e cinco anos e meio, foi a suprema lei a reger o Brasil. Nenhuma outra constituição brasileira teve vigência tão longa, ficando aquém dela no

* Conferência proferida em 5 de maio de 1975 na Faculdade de Direito de Fortaleza. 
mínimo um quarto de século, posta de lado por fictícia a vigência da Constituição de 1891 após a promulgação do Decreto $n^{\circ}{ }^{0} 19.398$, de 11 de novembro de 1930 .

A permanência da Carta de 1824 por tanto tempo em vigor terá sido fruto de mero acaso? Decorrência do fato de que o tempo fluía mais lento no século dezenove brasileiro? Não seria essa estabelidade resultante, em grande parte, das próprias virtudes do texto? Do realismo e do equilíbrio inscritos em suas linhas? Da adequação de seu modelo à realidade brasileira?

Essas indagações e outras que delas se aproximam ou a elas se associam desafiam o estudioso da história constitucional, e política, brasileira. Respondê-las não é apenas conhecer melhor o passado, é, quem sabe, encontrar um veio de autenticidade que poderá iluminar o futuro.

Por essa razão, a análise do modelo político da Constituição do Império não é apenas um preito comemorativo dos cento e cinqüenta anos de sua edição. Serve também de alicerce para pesquisas sobre o futuro das instituições. Não é o passado a raiz do futuro?

Seria mister um livro e não apenas uma conferência para estudar, com a devida profundidade, as instituições imperiais. Ciente de suas limitações, este trabalho buscou apenas examinar alguns aspectos salientes, assinalando e sublinhando especialmente a dinâmica traçada no próprio corpo da Carta.

\section{A Fonte do Poder Político.}

2. Se a coerência ideológica fosse indispensável para a estabilidade de uma constituição, certamente ninguém vaticinaria para a Carta de 1824, uma longa vida.

No plano lógico, o ponto de patrida de qualquer constituição é a determinação da origem do Poder. Nisto transpa- 
rece o princípio de soberania que legitima as instituições e inspira a sua estruturação natural.

Ora, o preâmbulo da Carta, por não se contentar com um princípio mas procurar o apoio de dois, já demonstra o que, na ordem das idéias, é uma fraqueza mas, na ordem dos fatos políticos, talvez seja contribuição para a firmeza. De fato, esse preâmbulo invoca, lado a lado, o princípio monárquico e o princípio popular, como fonte primeira do Poder do príncipe outorgante.

E "Dom Pedro Primeiro, por graça de Deus e unânime aclamação dos povos" que oferece, jura e manda cumprir a Constituição. Espalda-o a graça de Deus, portanto, o direito divino que o unge como Bragança, através da história. $\mathrm{E}$ também a aclamação dos povos, a vontade geral que manifesta o seu consentimento.

Sem dúvida, a origem divina do Poder não exclui a participação popular no seu estabelecimento. Essa era, aliás, a lição de TOMÁs DE AounNo, ao interpretar o célebre texto de SÃo Paulo na Epístola aos Romanos (13,2) segundo o qual "não há autoridade que não venha de Deus" Para o Doutor Angélico, com efeito, o Poder provém de Deus como autor da natureza humana. Deus quis o Poder, tendo feito o homem tal qual ele é. Contudo, se a necessidade do Poder para a sociedade decorre diretamente da vontade divina, as formas históricas de que se reveste esse Poder, e especialmente a sua atribuição a quem 0 exerce num determinado momento, tudo isto é de origem humana da vontade do homem. Dessa forma, para o Aquinate, todo o Poder vem de Deus mas por intermédio dos homens.

Seria, contudo, deturpar inteiramente o pensamento que inspirou a Carta de 1824 pretender que o mesmo se fundasse na lição do sábio dominicano. Pedro I estava seguramente imbuído que seu Poder provinha de Deus, ainda que pelos caminhos tortuosos da Providência. 
Não podia olvidar, entretanto, que o seu justo título era o trono do Reino Unido como sucessor de seu pai, Dom João VI. Faltava-lhe, para um Brasil independente, ainda vivo e reinante o seu genitor.

Por outro lado, não podia ignorar a aceitação cada vez mais ampla dos princípios da soberania nacional, e da soberania popular, que, logicamente distintos, eram difundidos na confusão de uma obscuridade conveniente, pelo constitucionalismo. Dessa forma, nāo era despiciendo o auxílio que a aclamação dos povos trazia à graça de Deus para fortalecer o Poder de Pedro I.

3 Essa duplicidade, todavia, não está presente apenas no preâmbulo da Carta. Ela penetra o texto inteiro. De fato, neste coexistem o princípio aristocrático, fundado no direito divino, na graça de Deus, e o princípio democrático, apoiado na aclamação dos povos. Logicamente essa contradição deveria abalar e enfraquecer as instituições, historicamente isso não ocorreu.

O gênio da Carta de 1824 e, sobretudo, a razão de sua longa vida está na conciliação dos dois princípios contraditórios que o texto ensejou e a prática, felizmente estabeleceu: o princípio autocrático pelo qual o Poder se distribui da cúpula para a base da hierarquia de autoridades; o princípio democrático segundo o qual o Poder sobe do mais baixo para o mais alto.

Tal se vê claramente da análise da divisão de poderes que a Constituição consagra.

Como é sabido, a Carta de 1824 não se contentou com a tripartição de poderes à moda de Montesquieu. Previu não três mas sim quatro poderes, acrescendo ao Legislativo, ao Executivo e ao Judicial, o Moderador (art. 10) Seguiu nisso a lição de Constant, como, por exemplo, expõe o primeiro capítulo do Cours de Politique Constitutionnelle. 
Ora, na atribuição desses poderes, o princípio autocrático prevalece quanto ao Moderador, delegado ao Imperador (art. 98), quanto ao Executivo, de que é o chefe o próprio Imperador (art. 102) e até em relação do Judiciário, cuja independência, entretanto, se salvaguarda (art. 151) Por sua vez, o princípio democrático prepondera apenas relativamente ao Legislativo que é, contudo o poder político por excelência.

Basta o apontado para mostrar que a Constituição é basicamente uma Carta autoritária. Seu caráter autocrático, porém, é adoçado na regulamentação dos institutos e, sobretudo, foi atenuado pela prática. De qualquer forma, o reconhecimento de direitos individuais intangíveis limita o âmbito desse autoritarismo benevolente.

E o que resulta do exame da mecânica da Constituição conforme se vai demonstrar.

\section{O Princípio Autocrático}

4. Na lógica da Constituição, não se esconde a posição proeminente do princípio autocrático. Tal reponta antes de mais nada pela importânciaa conferida ao Poder Moderador que é delegado ao Imperador.

A existência de um Poder Moderador é, sem dúvida, o ponto mais saliente da Carta de 1824. E a primeira característica que acode à memória dos que a ela se referem, é o que a faz conhecida e comentada, inclusive por autores contemporâneos estrangeiros. MAURICE DUvERGER, por exemplo, ao analisar as instituições da Quinta República, que, a seu ver, exprimem no tocante à função do Chefe de Estado as concepções de Constant, recorda e elogia a nossa primeira Constituição (La Cinquième Rèpublique, Paris, P U.F , 1960, p. 177/178.)

A necessidade de um quarto Poder, de um Poder Moderador, foi difundida por Constant, cuja atenção fora desper- 
tada pelos conflitos entre poderes que a experiência da "separação" ensejara. Na verdade, a possibilidade de tal desencontro fora entrevista por MonTEsquieu. Este, porém, a minimizou, não prevendo qualquer mecanismo para a sua solução.

De fato, Montesquieu, no célebre cap. VI do Título XI do Espírito das Leis, denominado " $\mathrm{Da}$ Constituiçāo da Inglaterra" onde aparece a divisão clássica, menciona essa possibilidade, ainda que de passagem. Depois de descrever as três funções - a legislativa, a administrativa e a jurisdicional e sua estruturação em três poderes harmônicos e independentes, reconhece o mestre: "Esses três poderes deveriam formar um repouso ou inação. Mas, como pelo movimento necessário das coisas, são constrangidos a ir adiante, serão forçados a caminhar de comum acordo" Assim, admite o desacordo mas com ele não se preocupa, já que, supõe, naturalmente o mesmo se resolverá por um acordo imposto pela força das coisas.

Ao otimismo de Montesquieu contrapõe Constant uma visão, não pessimista mas sim realista, resultante da expeiiência com a prática da "separação", experiência que obviamente faltava ao autor do Espírito das Leis. A experiência de que os conflitos entre poderes nem sempre se resolvem natural e espontâneamente e que muita vez servem para ensejar a destruição do regime constitucional.

Escreve Constant: "O poder executivo, o poder legislativo e o poder judiciário são três molas que devem cooperar, cada uma de sua parte, para o movimento geral: mas quando essas molas desarranjadas se cruzam, se entrechocam e se entravam, é preciso uma força que as reponha em seu lugar. Esta força não pode estar numa das molas, pois lhe serviria de meio para destruir as outras. E preciso que esteja fora, que seja neutra de algum modo, para que sua ação se aplique necessariamente em toda a parte em que é necessário que seja aplicada, e para que seja preservadora, reparadora sem ser 
hostil" (In Principes de Politique, 1815, cap. II, De la nature du Pouvoir Royal)

Ter-se-ia então um poder que servisse de árbrito nos conflitos entre os outros. Um poder que os conciliaria, para que caminhem concertados. Tal poder seria naturalmente o que cabe ao monarca, o único que pode ser neutro, porque seu interesse está no bom andamento dos negócios públicos. Daí o nome de Poder Neutro ou de Poder Real que o quarto poder recebe na obra do ilustre pensador liberal.

5. As idéias de Constant ao servirem para a moldagem da Carta Constitucional sofreram uma certa deturpação como aponta, com a segurança de mestre consumada, o Prof. Paulo Bonavides no seu estudo $O$ Poder Moderador na Constituição do Império (In Reflexões - Política e Direito, Fortaleza, 1973, p. 227 e segs.)

A previsāo de um quarto poder, o Moderador, não aparece no Projeto apresentado por ANTônio Carlos à Assembléia Constituinte de 1823. Entretanto, consoante aponta ainda o Prof. Bonavides arrimado em Afonso Arinos, foi esse Andrada que melhor apreendeu a lição de Constant. Com efeito, na sessão de 23 de julho de 1823 da Assembléia Constituinte, procurando contrastar a situação do Legislativo em face da Coroa, observa ele: "Procurei a origem desta influência e encontrei-a na necessidade de um poder vigilante e moderador nos governos representativos. Mostrei que este poder que, como atalaia da liberdade e direito dos povos, inspeciona e contrabalança todos os demais poderes para que se, contenham nos limites marcados por sua mesma natureza, e não se tornem danosos à Naçāo, não fora desconhecido dos mais sábios legisladores da antigüidade. Que, nas Repúblicas, ele deveria estar separado do Chefe da Nação, mas, nas monarquias constitucionais, era dela inseparável, para o conservar na alta preeminência em que esta forma de governo necessariamente o coloca" (Apud Bonavides, ob. cit.). 
Igualmente não aparece esse quarto Poder no projeto submetido ao Conselho de Estado. Segundo Paulino JacQUES, foi num anteprojeto redigido por MarTim Francisco que por primeiro se previu um poder moderador. E foi através desse trabalho que Pedro I sentiu a importância da instituição cuja adoção recomendou nos subsídios oferecidos ao Conselho de Estado. Assim se deu sua incorporação ao texto promulgado e jurado a 25 de março de 1824 (Cf. Do relacionamento dos Poderes Políticos na Constituição do Império, in Revista da Informação Legislativa, Senado Federal Brasília, ano VI, n. ${ }^{\circ} 41$ )

6. Na Carta de 1824, é o art. 98 que define as funções do Poder Moderador, atribuindo-o ao Imperador. Assim reza o texto: "O poder moderador é a chave de toda a organização política, e é delegado privativamente ao Imperador, como chefe supremo da nação e seu primeiro representante, para que incessantemente vele sobre a manutenção da independência, equilíbrio e harmonia dos mais poderes políticos"

Comentando-o, escreveu Pimenta Bueno uma página digna de reprodução pela clareza e precisão com que descreve a natureza e finalidade da instituição: "O poder moderador . é a suprema inspeção da nação, é o alto direito que ela tem, e que não pode exercer por si mesma, de examinar o como os diversos poderes políticos que ela criou e confiou a seus mandatários, são exercidos. E a faculdade que ela possui de fazer com que cada um deles se conserve em sua órbita, e concorra harmoniosamente como outros para o fim social, o bem ser nacional; é quem mantém seu equilíbrio, impede seus abusos, conserva-os na direção de sua alta missão; é enfim a mais elevada força social, o órgão político mais ativo, o mais influente, de todas as instituições fundamentais da nação" (Direito Público Brasileiro e Análise da Constituição do Império, ed. Min. da Justiça, Rio de Janeiro, 1958, p. 201).

Destarte, o Poder Moderador é o primeiro dos poderes "chave de toda a organização política" no arranjo institucional. 
Cabe ao Imperador como "primeiro representante" da Nação. Fortalece-o, for sua vez, a inviolabilidade e a irresponsabilidade que a graça de Deus, ou seja, o princípio monárquico associa à sua pessoa e o art. 99 da Constituição consagra.

Na pureza da doutrina, deveria estar o Poder Moderador separado de qualquer outro. Somente assim se asseguraria a independência dos poderes bem como a imparcialidade indispensável a um árbitro. Todavia, na Carta de 1824, o Imperador não recebe exclusivamente o Poder Moderador mas igualmente a chefia do Executivo. Isto deu lugar a uma crítica, ponderada e justa, de Pimenta Bueno. Assinala o grande constitucionalista do Império: "Na maior parte das monarquias constitucionais e representativas o poder moderador está reunido ao poder executivo, de quem forma a parte a mais elevada, e que é exercida pela coroa, pela ação e direção do monarca. E, porém, mais lógico e conveniente não confiá-lo, e menos confundi-lo, com nenhum outro poder, por isso mesmo que ele tem de inspecionar a todos, já sobre seu exercício próprio, já sobre suas relações recíprocas" (Ob. cit., p. 202).

Ressalte-se, por outro lado, que o Imperador recebe o Poder Moderador não apenas por força do princípio monárquico. Cai-lhe nas mãos esse poder também porque é ele o primeiro representante da nação, no que transparece senão o princípio democrático pelo menos uma entorse ao direito divino. Repontam aqui as idéias de SIEyk̀s sobre a soberania da nação cuja expressão maior está na concepção de que a representação da vontade nacional pode ser estabelecida independentemente de eleição.

7. Segundo a Carta de 1824 , no art. 101, compete ao Poder Moderador: $1 .^{\circ}$ ) Nomear os senadores, dentre os nomes indicados segundo o preceituado na própria Constituição e que se examinará adiante; $2^{\circ}$ ) Convocar extraordinariamente a Assembléia, pois ordinariamente esta se reunirá independentemente de convocação cada 3 de maio (art. 18) ; $3 .^{\circ}$ ) Sancionar as deliberações da Assembléia para que tenham 
força de lei; $4 .^{\circ}$ ) Aprovar ou suspender inteiramente as decições dos conselhos provinciais; 5.0) Prorrogar a sessão da Assembléia, ou adiá-la, exigindo-o a salvação do Estado, ou dissolver a Câmara dos Deputados, convocando eleição de nova, imediatamente; $6^{\circ}$ ) Nomear e exonerar livremente os ministros de Estado; $7^{\circ}$ ) Suspender os magistrados nos casos previstos na própria Carta; $8^{\circ}$ ) Perdoar ou comutar as penas; 9..$^{\circ}$ Conceder anistia em caso urgente.

$E$ de se indagar se todas essas funções se compatibilizam com a neutralidade do quarto poder imaginado por BENJAMIN Constant. Paulo Bonavides, para apenas citar um mestre, entende que não. Para este, "dissolver a Câmara dos Deputados, prorrogar ou adiar a Assembléia Geral, nomear Senadores e nomear e demitir livremente os Ministros de Estado, não se compatibilizava de modo algum com aquele quarto poder da filosofia política de Benjamin Constant, a tutelar um liberalismo puro e sem mácula" (Ob. cit., p. 232) De fato, não parece próprio a um poder neutro ou arbitral nomear Senadores e Ministros, ou exonerar estes últimos.

Parece claro, por isso, que a competência do Poder Moderador, na Constituição do Império, não reflete apenas as concepçōes de Constant. Serve, também, de meio de expressão do princípio autocrático.

Com efeito, é o Imperador, como primeiro representante da nação, quem exerce o Poder Moderador, ponto mais alto da organização política. Não é de surpreender, portanto, que através dele se manifeste o princípio autocrático. Que, assim, de cima para baixo, se estruture o Executivo ou se selecione a Câmara Alta.

8. Não se olvide, contudo, que a Carta, se atribui ao Imperador a chefia do Executivo como lhe delega o Poder Moderador, não o faz nos mesmos termos. Realmente, enquanto o Poder Moderador "é delegado privativamente ao Imperador", a chefia do Executivo é confiada ao Imperador, 
para que o exercite por meio de seus ministros. E a lição segura e insofismável de Pimenta Bueno: "O imperante sem o ministro não é poder executivo, nem os atos deste poder têm vigor sem a assinatura ministerial, sem a responsabilidade, qque é garantia indispensável da sociedade" (Ob. cit., p. 208).

E ainda uma vez o ensinamento de Constant que há de esclarecer o alcance do texto. O Poder Executivo simplesmente emana do monarca, não permanece nele, que não o exerce. Ou na fórmula sintética por ele empregada no Cours de Politique Constitutionnelle, (cap. I) : O poder Executivo, "embora emane do rei, não é mais o rei, do que o poder representativo não é o povo, conquanto emane do povo".

Assim, o Imperador é chefe do Executivo, mas chefe nominal, pois não lhe cabe senão uma vigilância ou supervisão sobre o seu exercício. Este cabe aos ministros que o Imperador nomeia e exonera, não, contudo, como chefe do Executivo e sim como detentor do Poder Moderador (art. 101, 6. ${ }^{\circ}$ ).

O verdadeiro caráter da chefia do Executivo por parte do Imperador se tornou mais claro ainda com a criação da Presidência do Conselho de Ministros, por lei de 1847 Tendo cabeça própria, o Ministério não fugia à supervisão imperial: era quem, todavia, na rotina de todos os dias, guiava a máquina administrativa.

Estabelecia-se com isto um parlamentarismo de tipo orleanista, em que o gabinete deveria reunir a confiança do Imperador e da representação popular. Tal parlamentarismo tanto bem quanto mal se praticou no segundo Império, ainda que falseado, especialmente pelas deficiências do processo cleitoral.

\section{IV o Princípio Democrático.}

$9 \mathrm{Na}$ Carta de 1824, o ponto onde, palidamente embora, se manifesta o princípio democrático, é o Poder Legis- 
lativo. De fato, na estruturação deste, cabe ao povo uma representação.

Esta representação, entretanto, não é propriamente do povo e sim da nação, conforme afirma o art. 11 e confirma o art. 12 da Constituição. Prevalece nisto o pensamento de SIEYÈs, com a doutrina da soberania nacional e sua decorrência: a do mandato representativo.

Para o famoso autor do Qu'est-ce que le tiers état?, o supremo poder num Estado não pertence ao povo, cabe à nação que com ela não se confunde. Aqui está o ponto fundamental. Para StEYÈs, nação e povo são realidades distintas. Enquanto aquela é permanente, este é sua encarnação transitória e passageira. Possui a primeira interesses que transcendem os das gerações que se sucedem. Por isso, o interesse do povo nem sempre coincide com o da nação, não raro a este se opõe. Por isso, a vontade do povo nem sempre exprime a vontade da nação. Esta se identifica com a razão: a soberania da razão; enquanto aquela muitas vezes se confunde com a paixão. $\mathrm{Nu}$ ma fórmula poética, o povo são os vivos, a nação, os vivos, os mortos, os ainda por nascer.

Em virtude disto, é a vontade da nação que deve governar. Para exprimi-la, é que hão de existir os representantes, da nação e não do povo. Assim, a qualidade de representante não importa necessariamente numa designação popular, como o exemplifica a própria Carta de 1824 ao atribuir essa qualidade ao Imperador (art. 11) Tais representantes devem exprimir a vontade da nação e não do povo, a de seus eventuais eleitores. Em suas deliberações, deve fazer-se ouvir a razão, o interesse geral permanente e não qualquer interesse particular ou conjuntural.

Daí a estrutura do mandato representativo, que, numa larga medida, ainda é a base sobre a qual se ergue a democracia contemporânea. O representante não fala em nome de seus eleitores mas de toda a nação. Deve seguir os ditames da 
razão e não eventuais instruções de seus eleitores, a que não deve explicações por suas opiniões e votos.

E certo que, em regra geral, esses representantes são eleitos pelo povo. Não em razão de um direito popular à participação nos negócios políticos e sim de uma função que o eleitor desempenha para a nação. Quem vota não está usando de um direito seu, de participar ou de influir nos negócios públicos, está escolhendo em nome da nação e por conta dela quem vai querer por ela, quem vai servir de órgão de expressão de sua vontade.

$\mathrm{Na}$ verdade, a escolha dos representantes é deixada, a título geral, ao povo, em aplicação de uma observação de Montesquieu. Diz este que, se nem todos são capazes de governar, cada um é capaz de escolher quem tem essa capacidade (Espírito das Leis, livro XI, cap. 6. $)$ Por isso, o povo, no todo ou em parte, recebe da nação essa tarefa: a de selecionar os representantes que vão falar pela nação.

Ora, não tendo o povo, nem cada indivíduo o direito de participar da gestão da coisa pública, cabendo-lhe apenas, segundo o entender a nação, a função de eleger os representantes desta, o voto e a elegibilidade podem ser restritos. Chega assim Sieyès a uma posição oposta à de Rousseau. Para este, somente seria legítimo o governo em que todos participassem da expressão da vontade geral. Para Sieyès, segundo a conveniência da nação, um grupo mais ou menos numeroso, escolhe quem vai falar pela nação.

10. Dentro dessas premissas, a Constituição do Império adotou o voto e a elegibilidade restritos, segundo um critério censitário, ao mesmo tempo que preferia o sistema de eleiçōes indiretas.

Todos os brasileiros que tinham a renda líquida de $100 \$$ gozavam do direito de votar nas assembléias paroquiais para a designação dos eleitores provinciais. Eram cidadãos 
ativos, conquanto não contassem com a elegibilidade (art. 92) . E certo que também eram excluídos da cidadania ativa os menores de 25 anos, exceto se casados, os oficiais militares, os bacharéis e os clérigos, os filhos-família que vivessem com os pais, exceto se exercessem cargo público, os empregados em geral exceto os guarda-livros, os administradores de fazendas e fábricas, os gerentes de casas de comércio e os servidores de mais alta categoria da Casa imperial.

Por outro lado, a renda mínima de $200 \$$ era necessária para ter o direito de voto na assembléia provincial e dessa forma eleger os representantes ao conselho provincial, os deputados e os senadores, dele excluídos os libertos e os criminosos desde que pronunciados (art. 94). Entretanto, para ser elegível como deputado, era necessário um mínimo de $400 \$$ de renda anual, excluídos outrossim os não católicos e os naturalizados (art. 95) E para chegar a senador, a renda exigida era de $800 \$$ anuais.

Como se vê, quem não tinha a renda anual mínima de $100 \$$ estava excluído de qualquer participação política. As rendas de 100 a $200 \$$ ensejavam o direito de votar para qualquer representação mas apenas a elegibilidade para os conselhos provinciais. A elegibilidade para a Câmara dos Deputados reclamava $400 \$$ e para o Senado $800 \$$.

Reduzido, pois, era o grau de democracia que comportavam as instituições imperiais.

11. Se isso não bastasse, o sistema eleitoral era extremamente falho.

A primeira lei eleitoral somente foi promulgada em 1846. Até então, as eleições observavam a regulamentação baixada pelo Executivo. Ora, como descreve, de modo colorido, Joño Camilo de Oliveira Torres, "o mais grave problema residia nas 'qualificações' $O$ povo escolhia por aclamação a mesa eleitoral, que, por sua vez, organizava as listas dos votantes... 
que votavam. $\mathrm{Na}$ realidade, escolhia-se a mesa a pauladas, e quem vencesse esta primeira batalha teria a vitória eleitoral de antemão assegurada..." (A Democracia Coroada, Ed. José Olympio, Rio de Janeiro, 1957, p. 293) .

Acrescente-se ainda que a investidura no Senado não resultava diretamente da vitória eleitoral. Com efeito, a eleição servia simplesmente para indicar uma lista tríplice da qual o Imperador retiraria um nome que seria o senador.

A lei de 1846 procurou melhorar o sistema na aparência sem alterá-lo no fundo. Admitiu, é certo, recurso ao Judiciário em caso de recusa de qualificação, o que, na prática, dada a lentidão dos tribunais, de quase nada servia.

Essa lei foi substituída pela de 19 de setembro de 1855 . Esta, devida, sobretudo, à influência do Marquês do Paraná, apresentava três características marcantes: as incompatibilidades eleitorais, a divisão das províncias em círculos de um deputado e a eleição de suplentes de deputados (Cf. João Camilo ob. cit., p. 297) Tal reforma, de fato, diminuiria a influência do governo sobre as eleições, tanto que sua primeiia e única aplicação resultou na vitória da oposição.

Esta referida lei foi alterada em 1860 . Suprimiu-se a eleição do suplente e substituiu-se o círculo de um deputado pelo de dois. Mantinha-se, porém, o problema da qualificação, à mercê das autoridades locais, que praticavam toda a sorte de abusos.

A grande reforma eleitoral do Império, porém, veio com a lei de 9 de janeiro de 1881, a chamada Lei Saraiva. Esta que teve como relator na Câmara o jovem deputado Rui BARBosA, envolveu alteração constitucional. Com efeito, para estabelecer a eleição direta, deu o voto a todos os brasileiros com renda superior a $200 \$$, excluídos os serventes de repartição pública e os praças de pré. Eliminava com isto a faixa dos eleitores primários, prevista no art. 90 da Carta. Tal foi possível, porque, como é sabido, o art. 178 da Constitui- 
ção dispunha que somente era "constitucional o que diz respeito aos limites e atribuiçōes respectivos dos poderes políticos e aos direitos políticos e individuais dos cidadãos; tudo o que não é constitucional pode ser alterado, sem as formalidades referidas, pelas legislaturas ordinárias" Ora, entendeu-se que a eliminação do eleitor primário não era matéria constitucional. Entretanto, indubitavelmente essa exclusão restringia ainda mais o número de participantes no processo político.

$\mathrm{Na}$ opinião de Jõ̃o CAmilo a lei Saraiva "equivale a uma revolução" E justifica: "Basta recordar que, além de eleição direta, estabelece condições que prenunciam a justiça eleitoral, restabelece os círculos de um só deputado, regulamenta as incompatibilidades, impõe penalidades rigorosas contra fraudes, alarga o voto aos naturalizados, acatólicos e libertos. E, principalmente, introduz os títulos eleitorais" (Ob. cit., p. 303) Surge, assim, com essa lei o alistamento eleitoral de caráter permanente.

Embora tenha representado um progresso, a lei Saraiva não eliminou a corrupção e a fraude do processo eleitoral. E. final, como disse Pedro II, "não é o vestido que torna vestal a Messalina, porém sim a educação do povo e, portanto, a do governo" (Cf. Jỗo Camilo, ob. cit., p. 302).

\section{O Modelo Político do Império.}

12. O exame até agora feito permite, à guisa de conclusão, esboçar e apreciar o modelo político da Constituição do Império.

João Camilo de Oliveira Torres batizou-o no título de um livro conhecido, como "a democracia coroada" Não parece ser isso, todavia, o que resulta da análise acima procedida. O modelo constitucional não é democrático. Nele prepondera nitidamente o princípio autocrático. E o Imperador, no mecanismo previsto, a mola mestra, já que a ele se delega o poder moderador justamente dito "chave da organização 
política" Disto lhe resulta a possibilidade de selecionar os senadores vitalícios, de designar os ministros. E soma ao poder moderador a chefia do Poder Executivo.

E certo que Dom Pedro II tenha usado com moderação os seus vastos poderes. Longe de ter inclinações absorventes e autoritárias, o segundb. Imperador preferia acompanhar de mais longe o funcionamento das instituições e o andamento dos negócios públicos, só intervindo de quando em vez. As suas intervenções eram, porém, incontestáveis. À luz da fraude e da corrupção eleitorais que campeavam, a alternância de partidos que sua vontade provocava foi até louvável. Nem por isso deixava de traduzir um comando de cima para baixo, autocrático, pois.

Assim, o modelo antes que uma "democracia coroada", estabelecia uma monarquia democratizante. Com efeito, o monarca detinha o cerne do Poder mas o exercia segundo as formas constitucionais, com uma certa participação dos governados. Do povo mas de um povo que contava com, pelo menos, 200\$ de renda anual.

13. Por outro lado a experiência é pouco probante para as virtudes de um poder moderador. Este, na teoria, é um árbitro a eliminar conflitos, a reconduzir os demais poderes ao rumo do interesse geral. Sua inspiração é, sem dúvida, louvável. Entretando, na história contitucional brasileira, serviu de caminho a influência do Imperador. Não atuou como elemento de equilíbrio entre poderes, mesmo porque era atribuído ao próprio chefe do Poder Executivo.

$E$ o que espelha bem a crise ocorrida com a dispensa do gabinete Zacarias. Foi Pedro II que afastou do poder um gabinete que tinha maioria na Câmara dos Deputados, que impôs outro em substituição e que respondeu à desconfiança parlamentar com a dissolução da câmara baixa. Deu ensejo ao sorites de Nabuco de ARAújo: "O poder Moderador pode chamar a quem quiser para organizar ministérios: esta pes- 
soa faz a eleição porque há de fazê-la; esta eleição faz a maioria" Destarte, não era o gabinete que se apoiava na maioria parlamentar: ele, criatura do Imperador, é que a criava nas eleiçōes.

Isto exprime bem a natureza do "parlamentarismo" imperial. O modelo constitucional não o previa mas o ensejava. A prática se encaminhou no sentido de seu estabelecimento. A criação da Presidência do Conselho de Ministros em 1847 muito contribuiu para tanto. As formas e formalidades, os ritos e o estilo do parlamentarismo ficaram patentes durante o segundo Império. Entretanto, no fundo, tudo isso, todo o parlamentarismo imperial dependia da boa vontade de Pedro II.

14 Se outros méritos não tivesse, a Constituição de 25 de março de 1824 apresenta um que não pode ser esquecido. Era dotada da flexibilidade necessária para servir a uma sociedade em lento, porém, contínuo processo de modificação. Por outro lado, definia um rumo preciso em direção aos valores liberais, preenchendo desse modo uma tarefa didática relevante. Com isso, infletiu as estruturas políticas e sociais num sentido modernizador, sem lutas nem choques maiores. Pacificamente. E nisto se encontra o seu maior título de glória.

De certa forma, a República representou o coroamento de sua obra. Trazendo a pouco e pouco o Brasil político do atraso colonial para o mundo de seu tempo, a prática da Carta propiciou a sua superação. Ensejou o prevalecimento do princípio democrático sobre o princípio autocrático na Constituição republicana de 1891 .

Por tudo isso, merece memória e reverência a Carta Imperial. 